\title{
DIAGNÓSTICO DA FRAGILIDADE AMBIENTAL EMERGENTE DO MUNICÍPIO DE ANASTÁCIO, MATO GROSSO DO SUL
}

\author{
Diagnosis of emerging environmental fragility in the municipality of Anastácio, Mato Grosso \\ do Sul
}

\author{
Diagnóstico de la fragilidad ambiental emergente del municipio de Anastacio, Mato Grosso do \\ Sul
}

Vanessa Aline Wagner Leite ${ }^{1}$

Lidiane Perbelin Rodrigues ${ }^{2}$

\footnotetext{
${ }^{1}$ Bacharela em Geografia pela Universidade Federal de Mato Grosso do Sul. Bolsista Capes e Mestranda em Geografia - Programa de Pós-graduação em Geografia - Fundação Universidade Federal de Mato Grosso do Sul - UFMS, Aquidauana, Mato Grosso do Sul, Brasil. email - vanessawleite@gmail.com

${ }^{2}$ Licenciada em Geografia pela Universidade Federal de Mato Grosso do Sul. Bolsista Capes e Mestranda em Geografia - Programa de Pós-graduação em Geografia - Fundação Universidade Federal de Mato Grosso do Sul - UFMS, Aquidauana, Mato Grosso do Sul, Brasil. email - lidiane_perbelin@ @otmail.com
}

\section{Resumo}

O município de Anastácio possui extensão de $2.940,6 \mathrm{~km}^{2}$, está situado na porção centro-oeste do estado de Mato Grosso do Sul, entre as coordenadas $20^{\circ} 25^{\prime} 00^{\prime \prime}$ e $21^{\circ} 05^{\prime} 00^{\prime \prime} \mathrm{S}$ e $56^{\circ} 10^{\prime} 00^{\prime \prime}, 55^{\circ} 20^{\prime} 00^{\prime \prime} \mathrm{O}$. O município possui fortes ligações culturais com a região nordeste do Brasil, caracterizada pela produção artesanal de farinha de mandioca realizada pela colonia de pernambucanos do município. Apesar da culturalidade dos pequenos produtores, ocorre no município de Anastácio uma massificação da produção bovina para leite e corte, o que vem incrementando o desmatamento das áreas de Cerrado. Frente a essa problemática, o presente trabalho busca analisar a Fragilidade Ambiental Emergente do município de Anastácio-MS adaptando as metodologias de Crepani et al (2001) e Ross (1994). Foram identificadas 4 classes de fragilidade para a área de estudo: Muito baixa, Baixa, Média e Alta. Nota-se que a Fragilidade Média foi fortemente influenciada pela pastagem, o que sugere que o município sofre com o alto nível de antropização.

Palavras-chave: Vulnerabilidade. Fragilidade. álgebra de mapas.

\begin{abstract}
The municipality of Anastácio has an area of $2,940.6 \mathrm{~km}^{2}$ located to the center-west portion of the state of Mato Grosso do Sul, between coordinates $20^{\circ} 25^{\prime} 00$ "and $21^{\circ} 05^{\prime} 00^{\prime \prime} \mathrm{S}$ and $56^{\circ} 10^{\prime} 00^{\prime \prime}, 55^{\circ} 20^{\prime} 00$ "W. The municipality has strong cultural links with the northeastern region of Brazil, characterized by the artisan production of manioc flour made by the Pernambucan colony of the municipality. Despite the cultural nature of the small producers, in the municipality of Anastácio there is a massification of cattle production for milk and beef, which has been increasing deforestation in the Cerrado areas. Facing this problem, the present work seeks to analyze the Emergent Environmental Fragility of the city of Anastácio-MS adapting the methodologies of Crepani et al (2001) and Ross (1994). Four classes of fragility were identified for the study area: Very Low, Low, Medium and High. It is noticed that the Middle Fragility was strongly influenced by the pasture, which suggests that the municipality suffers with the high level of anthropization.
\end{abstract}

Keywords: Vulnerability. Fragility. map algebra. 


\section{Resumen}

El municipio de Anastácio tiene una extensión de 2.940,6 km², está situado en el centro-oeste del estado de Mato Grosso do Sul, entre como coordenadas $20^{\circ} 25^{\prime} 00$ "e $21^{\circ} 05^{\prime} 00^{\prime} \mathrm{S}$ e $56^{\circ} 10^{\prime} 00$ " , $55^{\circ} 20^{\prime} 00^{\prime O} \mathrm{O}$. El municipio tiene fuertes vínculos culturales con la región nordeste de Brasil, caracterizada por la producción artesanal de harina de la mandioca realizada por la colonia de pernambucanos del municipio. A pesar de la culturalidad de los pequeños productores, ocurre en el municipio de Anastácio una masificación de la producción bovina para leche y corte, lo que viene incrementando la deforestación de las áreas de Cerrado.Frente a esta problemática, el presente trabajo busca analizar la Fragilidad Ambiental emergente del municipio de Anastácio-MS adaptando las metodologías de Crepani et al (2001) y Ross (1994). Se identificaron 4 clases de fragilidad para el área de estudio: Muy baja, Baja, Media y Alta. Se nota que la Fragilidad Media fue fuertemente influenciada por el pasto, lo que sugiere que el municipio sufre con el alto nivel de antropización.

Palabras-clave: Vulnerabilit. Fragilidad. álgebra de mapas.

\section{Introdução}

Anastácio está localizado na microrregião de Aquidauana, Pantanal Sul, no sudoeste do Estado de Mato Grosso do Sul, à 140km da capital Campo Grande. Possui 2.940,6km² de extensão situados entre as seguintes coordenadas geográficas $20^{\circ} 25^{\prime} 00^{\prime \prime}, 21^{\circ} 05^{\prime} 00^{\prime \prime}$ de latitude Sul e 56 $10^{\prime} 00^{\prime \prime}, 55^{\circ} 20^{\prime} 00^{\prime \prime}$ de longitude Oeste (Mapa 1). O município faz divisa ao norte com Aquidauana, ao leste com Dois Irmãos do Buriti, ao sul com Nioaque, e a oeste com Bonito e Miranda.

Possui uma população de 23.835 habitantes, sendo pouco mais de 19 mil habitantes na área urbana de acordo com o levantamento do censo de 2010 (IBGE, 2017). Seu sitio urbano localizado no extremo norte do município faz fronteira com a cidade de Aquidauana, limitada naturalmente pelo Rio Aquidauana.

A cidade de Anastácio surgiu como um bairro de Aquidauana, denominado Margem Esquerda, situado nas proximidades da Ponte Roldão de Oliveira conhecido como Ponte Velha ou ponte da Amizade. Joia (2000) afirma que o espaço urbano dessas cidades teve como marco de sua evolução a construção da estrada de Ferro Noroeste do Brasil, a instalação do Quartel ( $9^{\circ}$ Batalhão de Engenharia e Combate Carlos Camisão), ascensão da atividade 
pecuária na macrorregião do Alto Pantanal, a pavimentação da BR 262 e o crescimento da atividade turística regional.

Anastácio foi elevado à categoria de distrito e posteriormente desmembrado do município de Aquidauana pela Lei n 2143 de 18 de março de 1964 e finalmente emancipada em 08 de maio de 1965 (JOIA, 2000).

Mapa 1- Localização do município de Anastácio no estado do Mato Grosso do Sul.

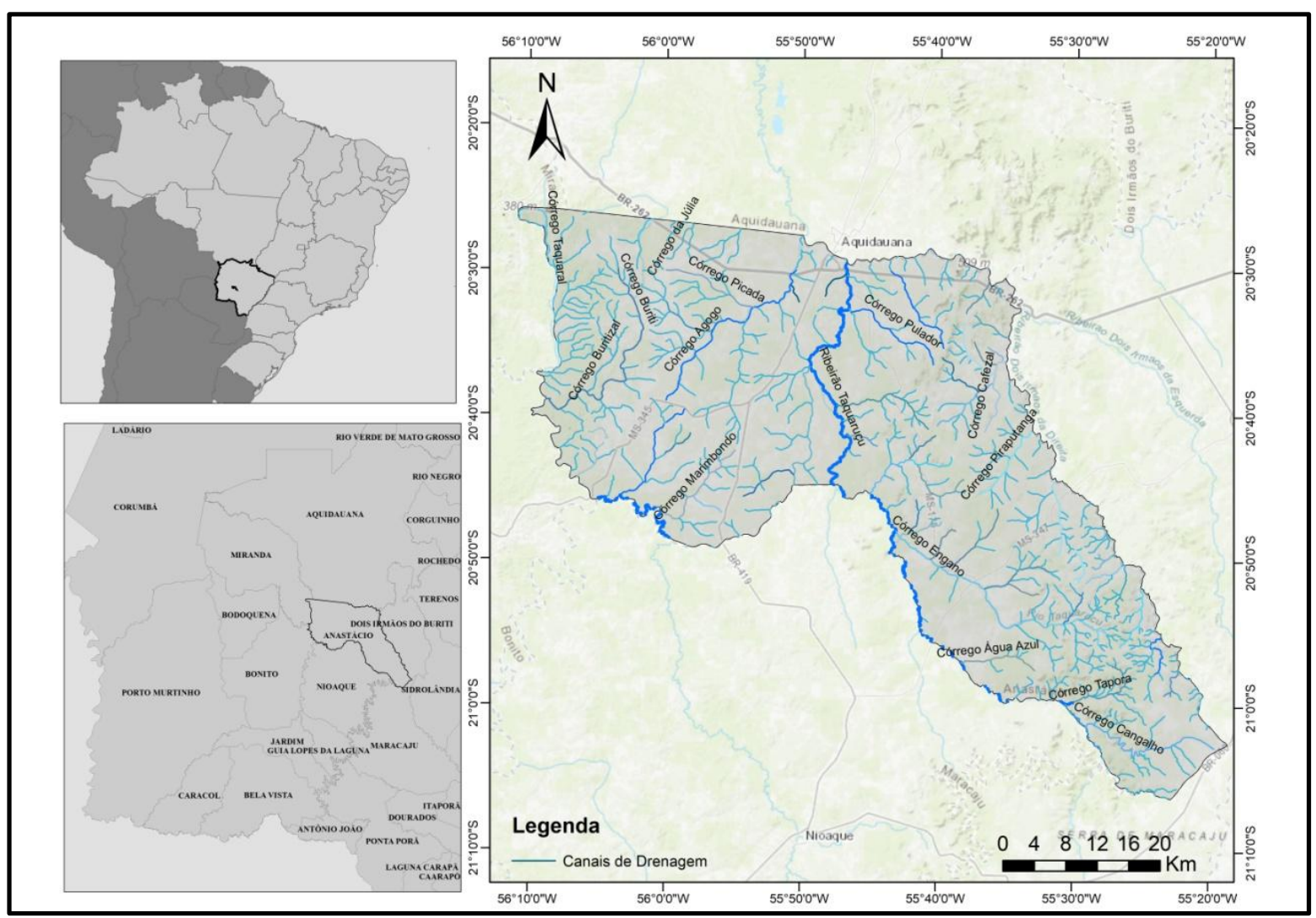

Fonte: Elaborado pelos autores (2018)

A população local possui fortes vínculos culturais com a região Nordeste, uma vez que a ocupação das áreas rurais do munícipio deu-se pelos colonos pernambucanos. Desde 2006 a prefeitura Municipal de Anastácio promove a Festa da Farinha, um evento que celebra as tradições culturais de seus moradores, com ênfase na gastronomia para comemorar o aniversário de emancipação do município (SILVA, MARQUES e MARINI, 2012).

Apesar da influência na cultura anastaciana, (produção de mandioca e a fabricação da de farinha artesanal nas colônias rurais) ser uma fonte de renda para pequenos produtores rurais, a maior força econômica de Anastácio é a produção leiteira e de gado de corte dos assentamentos, colônias e das fazendas. 
A ocupação massiva do território municipal para a criação bovina levou ao avanço do desmatamento e substituição da vegetação nativa de cerrado por forrageiras exóticas. Tendo em vista o impacto dessa mudança ocorrida no munícipio nos últimos 50 anos, o presente trabalho busca analisar a Fragilidade do município frente aos processos degradantes de erosão acelerada provocada pelas ações antrópicas e a degradação do Cerrado no munícipio de Anastácio.

\section{Materiais e métodos}

Os procedimentos metodológicos deste trabalho foram realizados conforme os níveis da pesquisa geográfica de Libault (1971), compilatório, correlatório, normativo e semântico. A compilação dos dados para a o município de Anastácio foi realizada e incorporada a um banco de dados geográficos utilizando o software ArcGis® 10 para a manipulação dos dados coletados.

Foram utilizados para a elaboração do mapa de fragilidade ambiental emergente, dados de Geologia, Solos, Declividade, Uso e Cobertura Vegetal e Erosividade recortados para o interior da área de estudo. Para o mapa de geologia utilizou-se os dados vetoriais do Plano de Conservação da Bacia do Alto Paraguai (PCBAP, 1997) na escala de 1:250.000. Para o mapa de Solos compilou-se dados vetoriais para o município de Anastácio da Embrapa Solos elaborado no ano de 2009, na escala de 1: 100.000.

A Declividade foi elaborada a partir do Modelo Digital de Elevação (MDE), de 12,5m, oriundos do satélite japonês ALOS (Advanced Land Observing Satellite) sensor PALSAR disponível no site da Alaska Satellite Facility (UAF/NASA) (ALOS-PALSAR, 2018), nas quadrículas AP_26198_FBS_F6770_R1. dem.tif, AP_26621_FBS_F6760_R1.dem.tif, AP_26621_FBS_F6770_R1.dem.tif, AP_2704_FBS_F6760_R1.dem.tif, através da ferramenta (Spatial Analyst Tools/Surface/Slope) do ArcGis.

No mapa de Cobertura Vegetal e Uso da Terra foi empregado o mapeamento do Projeto GeoMs para o Estado de Mato Grosso do Sul realizado no ano de 2007 na escala de 1:100.000 (SILVA et al, 2011). As classes de vegetação foram reagrupadas em vegetação arbórea e vegetação campestre de acordo com o nível de cobertura do solo. Quanto ao uso da terra foram agrupadas em pastagem, agricultura e área urbana.

No mapa de erosividade foram utilizados os dados elaborados por Oliveira et al (2012) para o Estado de Mato Grosso do Sul aplicado através do cálculo do índice $\mathrm{EI}_{30}$, uma vez que esse elemento é dispendioso e de difícil elaboração devido à escassez de dados de pluviosidade para a área. Posteriormente, utilizando a ferramenta (Conversion Tools/ To 
Raster/Polygon to Raster) os vetores foram convertidos para matriz com tamanho 30x30m e reclassificados utilizando (Spatial Analyst Tools/Reclass/Reclassify) atribuindo pesos de fragilidade (Tabela 1) para Solos, Uso da terra e Cobertura Vegetal e Declividade proposto por Ross (1994), pesos para geologia de acordo com Crepani et al (2001) e pesos para erosividade conforme Carvalho (2008).

Tabela 1- Relação entre as os elementos da paisagem e as classes de fragilidades.

\begin{tabular}{|c|c|c|c|c|c|c|}
\hline Geologia & Solos & $\begin{array}{c}\text { Uso da terra e } \\
\text { Cobertura } \\
\text { Vegetal } \\
\end{array}$ & $\begin{array}{c}\text { Declividade } \\
(\%)\end{array}$ & $\begin{array}{l}\text { Erosividade } \\
\text { (MJ.mm.ha- } \\
\text { 1.h-1.ano-1) } \\
\end{array}$ & $\begin{array}{l}\text { Classes de } \\
\text { Fragilidade }\end{array}$ & (peso) \\
\hline ------- & Latossolo & $\begin{array}{c}\text { Vegetação } \\
\text { Arbórea } \\
\text { Corpos d'água }\end{array}$ & $<6$ & ------ & Muito baixa & 1 \\
\hline $\begin{array}{c}\text { Formação Serra } \\
\text { Geral (JKsg) }\end{array}$ & Argissolo & $\begin{array}{l}\text { Vegetação } \\
\text { Campestre }\end{array}$ & 6 a 12 & ------ & Baixa & 2 \\
\hline $\begin{array}{l}\text { Grupo Cuiabá } \\
\text { (PScb) }\end{array}$ & ------ & Agricultura & 12 a 20 & ------ & Média & 3 \\
\hline $\begin{array}{c}\text { Formação Botucatu } \\
\text { (Jb) } \\
\text { Formação } \\
\text { Aquidauana (Cpa) }\end{array}$ & $\begin{array}{l}\text { Planossolo } \\
\text { Plintossolo }\end{array}$ & Pastagem & 20 a 30 & $\begin{array}{c}7357<\mathrm{R} \leq \\
9810\end{array}$ & Alta & 4 \\
\hline $\begin{array}{l}\text { Aluviões Fluviais } \\
\text { (QHa) } \\
\text { Formação Pantanal } \\
\text { (Qp) }\end{array}$ & $\begin{array}{l}\text { Vertissolo } \\
\text { Neossolo } \\
\text { Gleissolo }\end{array}$ & Área Urbana & $>30$ & ------ & Muito Alta & 5 \\
\hline
\end{tabular}

Fonte: Adaptado de Ross (1994), Crepani et al. (2001) e Carvalho (2008).

Após a reclassificação dos mapas efetuou-se cálculo com o auxílio da ferramenta Raster Calculator para a equação (1).

Onde:

$$
F=\frac{G+U+S+D+E}{5}
$$

F: Fragilidade Ambiental Emergente;

$G$ : Fragilidade para Geologia;

$U$ : Fragilidade para Uso e Cobertura Vegetal;

$S$ : Fragilidade para Solos;

$D$ : Fragilidade para Declividade;

$E$ : Fragilidade para Erosividade.

\section{Resultados e discussão}

Da área total do município, $2.376,44 \mathrm{~km}^{2}(80,81 \%)$ estão inseridos na bacia hidrográfica do Rio Aquidauana e 585,21 km² (19,19\%) inseridos na Bacia Hidrográfica do Rio Miranda, importante tributário das águas da região planáltica da Serra de MaracajuCampo Grande para a planície pantaneira na Bacia Hidrográfica do Alto Paraguai. 
A rede de drenagem de Anastácio é composta por canais das bacias hidrográficas do Ribeirão Taquaruçu, afluente do Rio Aquidauana e demais córregos como córrego Acôgo, córrego Pulador, córrego Engano e córrego Piraputanga.

O clima para o município de Anastácio segundo a classificação climática de KöppenGeiger é do tipo Aw definido como chuvoso no verão e seco no inverno. A pluviosidade varia entre $750 \mathrm{~mm}$ a $1800 \mathrm{~m}$, sendo que no mês mais seco é inferior a 50mm (EMBRAPA, 2012).

A geologia do município (PCBAP, 1997) corresponde a seis classes de litologia, Formação Serra Geral (JKsg), Grupo Cuiabá (PScb), Formação Botucatu (Jb), Formação Aquidauana (Cpa), Aluviões Fluviais (QHa) e Formação Pantanal (Qp). Os solos de acordo com a Embrapa (2009) são compostos por Latossolos, Argissolos, Planossolos, Vertissolos, Neossolos e Gleissolos (painel 1).

Painel 1- Mapas da Caracterização Geoambiental da área de estudo.

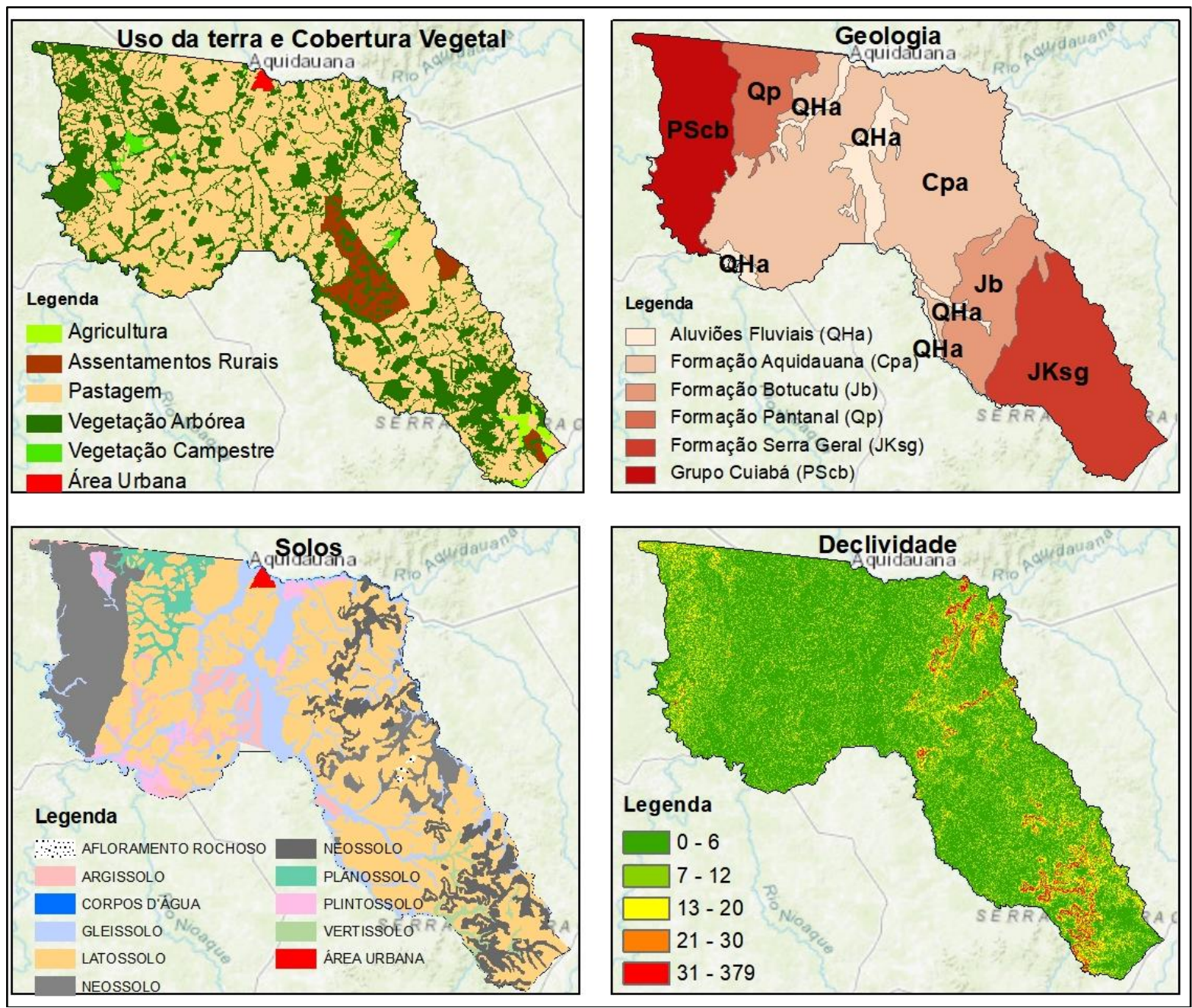

Fonte: Elaborado pelos autores (2018) 
A declividade varia entre muito baixa ( $<6 \%)$, baixa (6 a 12\%), média (12 a 20\%), alta (20 a 30\% e muito alta (>30\%). O uso da terra e cobertura vegetal apresenta vegetação fragmentada preservada nas áreas de restrição a ocupação como Área de Preservação Permanente (APP) como mata ciliar, topos de morro e áreas de reservas florestais na região dos assentamentos rurais. As áreas de pastagens representam mais da metade do território do município (61,3\%), o que denota ampla remoção das vegetações florestais e campestres na região. A classe agricultura representa os cultivos realizados nas pequenas propriedades dos assentamentos rurais e a classe área urbana corresponde a cidade de Anastácio.

Tabela 2- Quantificação das Classes de Fragilidade para a área de estudo

\begin{tabular}{ccc}
\hline \hline Classes de fragilidade & Área $\left(\mathbf{K m}^{\mathbf{2}}\right)$ & Área $(\boldsymbol{\%})$ \\
\hline \hline Muito baixa & 40,38 & 1,37 \\
Baixa & 804,80 & 27,40 \\
Média & 1975,69 & 67,27 \\
Alta & 116,39 & 3,96 \\
Muito Alta & 0 & 0 \\
\hline \hline
\end{tabular}

Fonte: Elaborado pelos autores com base nos mapas de Caracterização geoambiental (2018)

Realizado o mapeamento das variáveis: Geologia, Uso da terra e Cobertura vegetal, Declividade, Solos e Erosividade e efetuado a álgebra de mapas, obteve-se quatro classes de fragilidade: Muito Baixa, Baixa, Média e Alta, a classe Muito Alta não apresentou expressividade conforme hierarquização das classes (Tabela 2).

A classe de fragilidade Muito Baixa (mapa 3) corresponde a 1,37\% da área do município, ocorre predominantemente na porção sul sobre rochas extrusivas de baixa vulnerabilidade da formação Serra Geral. Nessa região desenvolvem-se Latossolos e Neossolos, a declividade varia entre 6 a $20 \%$ e os fragmentos de vegetação arbórea oferece proteção à erosão hídrica para o solo. A classe de fragilidade Baixa: ocupa 27,40\% da área de estudo. Essa classe tem grande influência da alta declividade na região sul, da alta vulnerabilidade da litologia da formação Aquidauana com sedimentos arenososconglomeráticos semiconsolidados a inconsolidados, do Arenito da Formação Botucatu e do baixo grau de proteção ao solo associado à pastagem. 
Mapa 3- Grau de Fragilidade Ambiental Emergente do município de Anastácio.

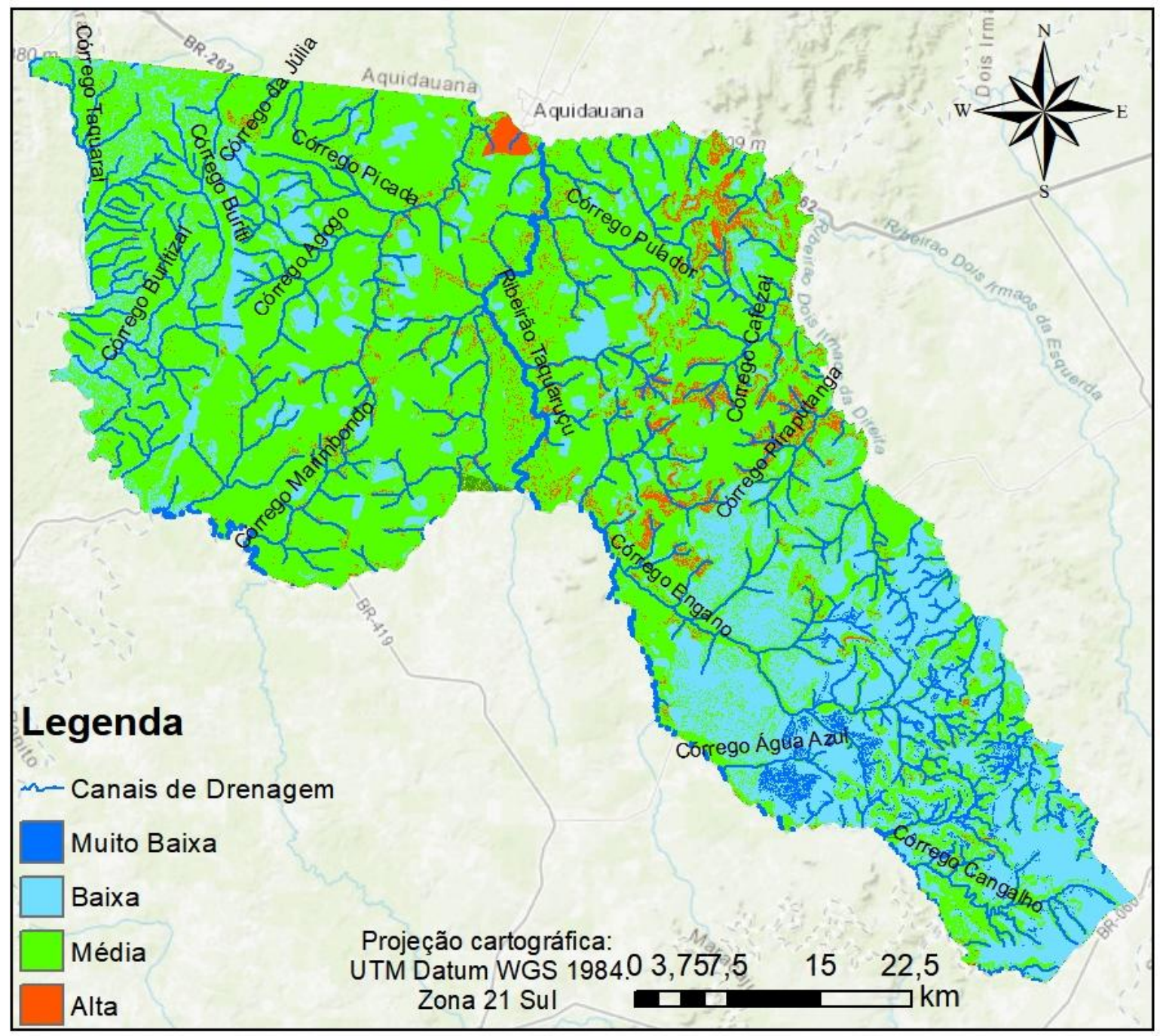

Fonte: Elaborado pelos autores (2018)

A classe de fragilidade Média apresenta predominância na área de estudo, com $67,27 \%$ da área sendo fortemente influenciada pelas características do uso da terra e cobertura vegetal (pastagem). Nessas condições, essa classe é formada sobre Latossolos de baixa vulnerabilidade e baixa declividade. A fragilidade Alta ocupa 3,96\%, esta classe corresponde a terrenos cuja declividade ultrapassa $30 \%$, fornecendo condições para a formação de solos jovens e altamente erodíveis como os Neossolos.

\section{Considerações finais}

O mapeamento da Fragilidade Ambiental Emergente demonstrou bons resultados quanto à adaptação da metodologia aplicada, visto que se trata de uma metodologia flexível a disponibilidade dos dados e de fácil aplicação. O município de Anastácio localizado na borda 
do Pantanal sul-mato-grossense apresenta-se intensamente antropizado em virtude da substituição crescente da vegetação nativa para satisfazer as necessidades das atividades agropastoris.

Quanto às taxas de fragilidade encontrada para a área de estudo, estas indicam que o município está inserido em uma zona de fragilidade natural elevada, com alta capacidade erosiva das chuvas, declividade acentuada, devido à presença da Serra de Maracaju e solos com alta susceptibilidade a erosão como os Neossolos.

Essas características, somadas ao uso antrópico, apontam que a área possui forte tendência de sofrer com a crescente degradação ambiental em virtude dos danos dos processos erosivos, sendo indicada para isso a criação de área de preservação permanente de acordo com a legislação vigente, além da adoção de práticas conservacionistas para o manejo do solo.

\section{Referências}

ALOS-PALSAR. Especificações Técnicas da plataforma. Alaska Satellite Facility. Disponível em: <http://www.eorc.jaxa.jp/ALOS/en/about/about_index.htm>. Acesso em: 25 Mar. 2018.

BRASIL. Plano de conservação da bacia do alto Paraguai: Análise Integrada e Prognóstico da Bacia do Alto Paraguai. Brasília: PNMA, 1997.

CARVALHO, N. O. Hidrossedimentologia prática. Rio de Janeiro, Editora Interciência, 2008.

CREPANI, E.; MEDEIROS, J. S.; HERNANDEZ FILHO, P.; FLORENZANO, Teresa Galloti.; DUARTE, Valdete; BARBOSA, C. C. F. Sensoriamento remoto e geoprocessamento aplicados ao Zoneamento Ecológico-Econômico e ao ordenamento territorial. São José dos Campos: INPE, 2001. Disponível em < https://goo.gl/RGo1DV> Acesso em 14 abr. 2017.

EMBRAPA, Solos. Empresa Brasileira de Pesquisa Agropecuária. Geoportal Digital. Disponível em https://goo.gl/S9T9F3>; Acesso em 14 abr. 2017.

EMBRAPA. Empresa Brasileira de Pesquisa Agropecuária. Zoneamento agroecológico do Município de Anastácio - MS. Centro Nacional de Pesquisa de Solos: Rio de Janeiro, 2009. Disponível em <https://goo.gl/rSfSaR> Acesso em 14 abr. 2017.

IBGE. CENSO DEMOGRÁFICO 2010. Características da população e dos domicílios: resultados do universo. Rio de Janeiro: IBGE, 2011. Disponível em: <https://goo.gl/EFmYKQ>. Acesso em: 10 Mai 2017.

JOIA, P. R. Bairros das Cidades de Anastácio e Aquidauana: Uma Proposta de Divisão do Espaço Urbano. Revista Pantaneira, Aquidauana, v.2, n. 1, p 27-32, 2000. 
LIBAULT, A. Os quatro níveis da pesquisa geográfica. Universidade de São Paulo, Instituto de Geografia, 1971.

OLIVEIRA, P. T. S.; RODRIGUES, D. B. B.; SOBRINHO, T. A.; CARVALHO, D. F. de; PANACHUKI, E. Spatial variability of rainfall erosive potential in the State of Mato Grosso do Sul, Brazil. Engenharia Agrícola, Jaboticabal, v. 32, n.1, p.69-79, jan./fev., 2012.

ROSS, J. L. S. Análise Empírica da Fragilidade dos Ambientes Naturais e Antropizados. Revista do Departamento de Geografia, São Paulo, n. 8, p. 63-74, 1994

SILVA, J. S. V.; POTT, A.; ABDON, M. M.; POTT, V. J.; SANTOS, K. R. Projeto GeoMS: cobertura vegetal e uso da terra do Estado de Mato Grosso do Sul. Campinas: Embrapa Informática Agropecuária, 2011.

SILVA, L. N.; MARQUES, H. R.; MARINI, B. O desenvolvimento local no município de Anastácio, MS: a Festa da Farinha - um estudo de caso. Multitemas, Campo Grande, n. 42, p. 115-128, jul./dez. 2012. Disponível em: 〈https://goo.gl/ogXh5y> Acesso em 20 mar. 2018. 